\title{
The role of the coasts in the economy of nations
}

\author{
R. Kerry Turner, Centre for Social and Economic Research on the Global Environment (CSERGE).School \\ of Environmental Sciences, University of East Anglia, Norwich, UK
}

Coastal zones are in the forefront of the impacts (positive and negative) of the globalisation process. The engine for the process whose pace and extent have inexorably risen over the decades is trade. Trade and its economic multiplier effects are a core feature of modern economic growth and increases in income. But stocks of wealth, including natural capital which underpin the economic activity may be being exploited unsustainably. The natural and other forms of capital located in coastal zones are clearly under severe pressure and are showing signs of significant stress and shock. Interdisciplinary or cross disciplinary research at a range of spatial scales needs to be augmented in order to underpin better policy responses.

Recent legislation has served to highlight the need to better corporate socio-economic assessment into coastal and marine planning and management strategies. Thus the EU Marine Strategy Framework Directive 2008/56/EC challenges the Community to assess the economic and social consequences of the use of coastal and marine resources and their degradation. This analysis must then be applied to inform a policy strategy which serves to protect the coastal/marine environment and encourages the sustainable use of the seas. The socio-economic decision support (DSS) set out in this presentation takes a strong sustainability position in that ecosystems are viewed as suppliers of a range on intermediate and final services through which humans benefit in welfare terms. Sustainable utilisation of the coastal/marine resources base is therefore the key notion. The DSS itself encompasses the ecosystem services approach (including economic monetary valuation of services benefits); together with a DP-S-I-R Scoping framework, futures scenario analysis and extended cost-benefit analysis.

The DSS is itself a component of an adaptive management process, a 'learning by doing' approach. Finally, it is emphasised that the assigning of monetary values to the benefits provided by 'healthy' ecosystems can serve to supplement (and not replace) scientific and ethical arguments in favour of environmental protection and biodiversity conservation. 